\title{
A produção de textos científicos explicativos na formação inicial de professores de Química
}

\author{
Isauro Beltrán Núñez \\ Sandra Cristina Bezerra de Barros \\ Universidade Federal do Rio Grande do Norte (Brasil)
}

\section{Resumo}

A explicação científica é essencial para a produção dos conhecimentos científicos e para a compreensão dos fenômenos e processos das ciências. Consequentemente, é um conhecimento profissional necessário para a atividade docente, e o professor de Química precisa dominá-lo para obter êxito em sua prática pedagógica, na educação básica. Este artigo objetiva caracterizar o conhecimento de estudantes do curso de licenciatura em Química sobre a explicação científica e a escrita de textos explicativos. $\bigcirc$ estudo foi realizado com 24 estudantes da disciplina Estágio e Prática de Ensino de Química II. Foi aplicada uma prova pedagógica com perguntas de conteúdo, relacionadas com as questões do estudo. Os resultados evidenciam um baixo domínio desse conhecimento docente assim como a necessidade de se atribuir importância à formação inicial dos graduandos quanto aos processos de comunicação da ciência, para que possam pensar sobre esses processos e aprender a ensiná-los no contexto da educação científica.

Palavras-chave: Escrever. Explicação científica. Conhecimento profissional. Licenciatura em Química.

\section{The production of explanatory scientific texts in Chemistry pre-service teaching education}

\section{Abstract}

Scientific explanation is essential for the production of scientific knowledge and for understanding scientific phenomena and processes. Consequently, it is necessary professional knowledge for the teaching activity, and the chemistry teacher must master it to succeed in his/her pedagogical practice in basic education. This article aims to identify and characterize the knowledge of undergraduate students in chemistry on the scientific explanation and the writing of explanatory texts. The study was carried out with 24 students enrolled in the Chemistry Practicum II course. A pedagogical test was applied with content questions related to the study questions. The results show a low domain of this teaching knowledge as well as point out the importance of the initial formation of undergraduates in the communication processes of science, so that they can think about these processes and learn to teach them in the context of scientific education. Keywords: Writing. Scientific explanation. Professional knowledge. Chemistry education. 


\section{La producción de textos científicos explicativos en la formación inicial de profesores de Química}

\section{Resumen}

La explicación científica es esencial para la producción de los conocimientos científicos y para la comprensión de los fenómenos y procesos de las ciencias. En consecuencia, es un conocimiento profesional necesario para la actividad docente, y el profesor de química necesita dominarlo para obtener éxito en su práctica pedagógica, en la educación básica. Este artículo objetiva caracterizar el conocimiento de estudiantes del curso de licenciatura en Química sobre la explicación científica y la escritura de textos explicativos. El estudio fue realizado con 24 estudiantes de la disciplina Práctica de Enseñanza de Química II. Se aplicó una prueba pedagógica con preguntas de contenido, relacionadas con las cuestiones del estudio. Los resultados evidencian un bajo dominio de ese conocimiento docente así como la necesidad de atribuir importancia a la formación inicial en cuanto a los procesos de comunicación de la ciencia, para poder pensar sobre esos procesos y aprender a enseñarlos en el contexto de la educación científica.

Palabras claves: Escribir. Explicación científica. Conocimiento professional. Licenciatura en Química.

\section{Situando a problemática do estudo}

A explicação científica é uma das práticas discursivas mais importantes na comunidade científica. Como prática epistêmica, é essencial para a produção dos conhecimentos científicos e para a compreensão dos fenômenos e processos das ciências. Consequentemente, é um conhecimento disciplinar sobre a natureza nas ciências, necessário para a atividade docente. Dessa forma, o professor de Química precisa dominá-lo para que obtenha êxito em sua prática pedagógica, na educação científica dos estudantes.

No entendimento de Lemke (1997), a ciência é um processo social com formas específicas de comunicação dentro de determinada comunidade científica. Ensinar ciências, dessa forma, para o autor, é ensinar os modelos e recursos da comunidade científica que permitem a comunicação científica, a partir dos quais se configuram padrões temáticos como redes de inter-relações de conceitos científicos, dentro de um campo semântico específico da área de ciências.

Jimenez-Aleixandre (2003) entende que aprender ciências é também se apropriar das linguagens que fazem parte da cultura científica, constituída ao 
longo dos séculos e transmitida por meio de textos escritos. Consequentemente, a enculturação científica (CARVALHO, 2010) dos estudantes deve também incluir atividades para a compreensão das explicações científicas e da escrita de textos explicativos produzidos pelos cientistas.

Nas aulas de ciências, os estudantes devem aprender a produzir diferentes tipos de textos, cada um com finalidades específicas. Como explica Márquez (2005), o aprendizado das ciências naturais deve estar vinculado à atividade de modelização com a produção de textos de diferentes tipos, os quais exigem diferentes habilidades cognitivo-linguísticas, e, dentre eles, a explicação.

São diferentes os estudos que têm evidenciado dificuldades dos estudantes para argumentar, explicar, justificar ou descrever em face de determinadas tarefas e situações que demandam essas habilidades (MARQUES, 2005; CARVALHO, 2010; DUSCHL, 1998). De acordo com Quilez (2016), a escola, de forma geral, tem delegado a aprendizagem da língua à disciplina de Língua Materna, desconsiderando o potencial e a importância da comunicação e da língua na aprendizagem das ciências e na compreensão da natureza do conhecimento científico. Os estudantes devem aprender a linguagem das ciências para compreender os seus processos e fenômenos e desenvolver um pensamento científico como parte de sua educação científica.

Lemke (1997) faz uma crítica ao ensino das ciências, no que diz respeito às habilidades comunicativas. Para ele, não é ensinado aos estudantes como falar e escrever utilizando a linguagem científica. Dessa forma, não se ensina como elaborar textos científicos funcionais, orais e escritos, por meio da explicação. Segundo ele, mostra-se apenas um conjunto de habilidades complexas e se espera que eles deduzam como se escrevem esses textos nas aulas de ciência.

Diversos estudos, dentre eles os de McNeill, Lizotte e Krajcick (2006), revelaram que, mesmo após vários anos de instrução em ciências, os estudantes apresentavam dificuldades para construir uma explicação científica. Um estudo com professores realizado por Jorba (2000) evidenciou dificuldades apresentadas por eles para produzir diferentes tipos de textos. Pozo e Postigo (2000), por sua vez, explicitam preocupações com o fato de, comumente, não se ensinar os estudantes a elaborar textos explicativos, dentre outros, quando se exige o domínio dessa habilidade de forma "implícita" nas aulas de ciências. 
McNeill, Lizotte e Krajcick (2006) têm ressaltado que a prática científica, como a explicação científica, deve ser ensinada de maneira consciente e explícita em sala de aula. Além disso, como têm mostrado Braaten e Windschitl (201 1), Núñez e Ramalho (2015), professores também têm dificuldades para construir explicações científicas.

Wenzel e Maldaner (2014) destacam a importância de maiores estudos e discussões sobre a escrita nos cursos de graduação em Química. Segundo os autores, a prática da escrita, nesses cursos, na maioria das vezes, pouco contribui efetivamente para a aprendizagem dos estudantes relativa à produção de textos científicos para aprender ciências, pelo fato de estar mais voltada para uma escrita geral sem considerar as especificidades da linguagem científica.

$\bigcirc$ objetivo geral da pesquisa realizada foi identificar e caracterizar o conhecimento de estudantes de um curso de licenciatura em Química sobre a explicação científica e a escrita de textos explicativos como uma habilidade importante a ser desenvolvida nos licenciandos em Química, o que poderá ajudar a repensar os processos de formação inicial de professores desse componente curricular na educação básica. A partir do objetivo geral, formulamos as seguintes questões que nortearam o estudo:

a) $\bigcirc$ que é, para os licenciandos, explicar propriedades das substâncias e dos materiais no contexto da produção do conhecimento científico da Química?

b) Quais conhecimentos profissionais se evidenciam nos textos explicativos produzidos pelos licenciandos em Química que tratam das propriedades físicas de substâncias e de materiais?

\section{A explicação científica e a habilidade de escrever textos explicativos na sala de aula de Química}

termo explicar remete a um conjunto variado de significados, o que evidencia seu caráter polissêmico. Seus significados são fundamentados em diversas perspectivas filosóficas, epistemológicas, linguísticas, didáticas, entre outras. Neste trabalho, focamo-nos nas explicações produzidas/elaboradas em ciências naturais, uma vez que pesquisamos o conhecimento de futuros professores de Química sobre essa habilidade cognitivo-linguística, necessária para ensinar os estudantes da educação básica a explicar e não serem apenas 
consumidores de explicações prontas e disponibilizadas nos livros didáticos, na aprendizagem da Química.

De acordo com Sanmartí (2007), o texto explicativo se caracteriza por ordenar determinados fatos segundo uma relação que, quase sempre, é de causa-efeito. Para Jorba (2000), explicar é apresentar raciocínios ou argumentos estabelecendo relações com base em determinado marco teórico, a partir das quais os fatos explicados ganham sentido e levam a modificar o estado do conhecimento. Márquez (2008) afirma que explicar consiste não só em relacionar os fatos entre si e com as ideias, mas também em produzir razões ou argumentos de maneira ordenada segundo uma relação de causa-efeito.

Gilbert (1999), define a explicação como:

[...] a capacidade de expressar os resultados do raciocínio próprio, justificar os raciocínios em termos de considerações evidentes, conceituais, metodológicas, com critérios definidos e de forma contextualizada, com argumentos coerentes. A explicação supõe fazer menção dos resultados, justificar procedimentos e apresentar resultados (GLLBERT, 1999, p. 27).

Considera-se que a explicação em ciências naturais constrói-se a partir da relação entre o observável e o não-observável, o concreto e o abstrato. o observável, o fenômeno, deve estar relacionado com o não-observável, ou seja, um nível de "essência" que, como teoria-modelo, fornece uma justificativa ao porquê de o fenômeno acontecer. Por isso, explicar implica diferenciar o fenômeno de sua essência e relacioná-lo a esta. Na estrutura da explicação, deve-se conectar o fenômeno com sua essência por meio de diversas relações de causa-efeito.

As explicações podem ser consideradas como meios pelos quais os cientistas relacionam observações de fenômenos com teorias científicas e propõem mecanismos causais para compreendê-los, prever futuros eventos ou fazer inferências sobre eventos passados, o que leva a concluir/admitir que as explicações sejam uma das práticas discursivas mais importantes da epistemologia científica.

Uma postura contemporânea sobre a explicação científica é o modelo cognitivo da ciência exposto por Giere (1988), o qual permite interpretar a ciência como uma atividade cognitiva relacionada à construção de conhecimentos. Esse modelo está centrado em como se desenvolve a atividade 
científica e a comunicação, especialmente a escrita. Nesse processo de produzir significados, os fatores cognitivos e sociais têm um papel essencial.

Na ótica da filosofia da ciência, um fato está explicado quando pode ser deduzido com base em leis científicas (Carl Henpell), quando é mostrado como um caso particular de leis mais gerais, ou seja, quando inclui outros casos que respondem à mesma essência, mas sendo aparentemente diferentes (Philip Kitcher) ou ainda quando se oferece uma descrição adequada de sua história causal (Wesley Salmon).

Os estudos da filosofia da ciência sugerem que uma única definição da explicação não consegue abarcar a diversidade de informações contidas em um texto explicativo. Para Nagel (1979), existem quatro tipos diferentes de respostas que são consideradas "explicativas": dedutivo, probabilístico, teológico e genético. Não obstante, nessa ampla categoria, muitas explicações podem ser tentativas de fornecer uma especificação do que acontece e/ ou da razão pela qual ocorre, como destacam Giere (1988) e Nagel (1979). Esse sentido geral do que é uma explicação causal é o mais adequado para explicar as propriedades físicas das substâncias e dos materiais, objeto do nosso estudo.

Na opinião de Gómez (2006), as explicações podem ser divididas de acordo com sua função: a) para ampliar um significado, b) para justificar, c) para descrever, d) para estabelecer causalidades. Norris, Guilbert, Smith, Hakimelahi e Phillips (2005) classificam as explicações científicas em: a) dedutivas, b) probabilísticas dedutivas, c) funcionais e d) genéticas ou narrativas.

Mortimer e Vieira (2010) distinguem a explicação como i) causal, ii) funcional e iii) intencional. Segundo Gilbert, Boulter e Rutherford (1998), de acordo com a pergunta que se procura responder, podem ser considerados cinco tipos de explicações, quais sejam: descritiva, intencional, causal, interpretativa e preditiva.

Neste estudo, assume-se a explicação como uma habilidade cognitivo-linguística em sua natureza epistemológica. As habilidades cognitivo-linguísticas, segundo Jorba (2000), são habilidades que se ativam e se manifestam na produção de textos, como no caso dos que demandam explicações cientificas. São habilidades que estão na base das operações intelectuais que se realizam constantemente na atividade de aprendizagem. 
A explicação na aprendizagem da Química pode ser considerada uma habilidade cognitiva-comunicativa, considerando a unidade dialética entre linguagem e pensamento (VYGOTYSTY, 1993). É uma habilidade cognitiva, pois ela se realiza (e ativa) sistemas de raciocínios do pensamento, na solução de determinadas situações-problema. É uma habilidade comunicativa, por sua vez, pois, por meio dela, se expressam pensamentos típicos da explicação em uma determinada situação comunicativa. Essa dualidade/unidade também se evidencia/está presente na unidade dialética dos processos de internalização-externalização da atividade cognoscitiva (NúÑ̃EZ, 2009).

Prat e Izquerdo (2000) entendem escrever como uma atividade básica em qualquer situação de aprendizagem, pois também é parte da atividade social de comunicação, necessária para ensinar e aprender. Em sala de aula, a produção de textos científicos explicativos por parte dos estudantes favorece a reflexão, um pensamento mais refinado, uma melhor compreensão dos conceitos científicos. Moraes, Galiaze e Ramos (2002) destacaram também o papel da escrita no sentido de possibilitar o domínio de abstrações para uma apropriação de um discurso mais qualificado.

Vygotsky (1993) fundamentou a importância da linguagem nos processos do pensamento ao estabelecer as relações dialéticas entre pensamento e linguagem. Na sua teoria, a linguagem tem um papel essencial nos processos de pensamento e, consequentemente, nas aprendizagens dos estudantes no contexto escolar. Ela é uma ferramenta por meio da qual se produz a comunicação, a própria elaboração dos conhecimentos e a regulação dos processos cognoscitivos e afetivos. Para ele, a escrita é uma forma de linguagem que influencia no desenvolvimento das funções psicológicas superiores e requer um nível de abstração diferente da linguagem oral. Quando se trata da escrita em ciências, há a exigência do domínio de um sistema simbólico complexo, a linguagem científica. Na visão desse teórico, a linguagem escrita é uma função verbal muito particular. É a álgebra da linguagem, possibilitando aceder ao plano abstrato mais elevado da linguagem, o que, por sua vez, reorganiza o sistema psíquico.

Dessa forma, Vigotsky (1993) confere à escrita um papel específico como ferramenta ótima para o desenvolvimento da função representativa da linguagem, como instrumento mediador da tomada de consciência, da autorregulação intelectual, do desenvolvimento e da construção do pensamento. $\bigcirc$ 
texto escrito possibilita "voltar atrás", revisar o escrito, refletir, fazer análises e sínteses, o que favorece as aprendizagens.

A escrita é, então, uma importante ferramenta para estruturar o pensamento e sua externalização, sendo diferente da linguagem oral (fala). Além disso, a linguagem escrita possibilita um desenvolvimento mais aprofundado da generalização teórica e da consciência.

Wenzel e Maldaner (2014) chamam a atenção para a importância da escrita e da reescrita orientada em aulas de Química, como uma boa prática para a apropriação e a significação da linguagem e a constituição do pensamento químico.

Lemke (1997) considera que, para obter o conhecimento da ciência por meio do diálogo, é necessário conhecer o que ele denomina de padrão temático do conteúdo científico. Isso significa que, para escrever em ciência, não é suficiente apenas conhecer os termos científicos, mas é preciso também combinar os significados, ou seja, construir o padrão temático em questão.

Para evitar o efeito da dispersão semântica no estudo (NÚÑ̃EZ; RAMALHO, 2000), como referência de padrão para escrever um texto explicativo sobre propriedades físicas de substâncias e de materiais em Química, adotou-se a base orientadora da ação explicar, proposta por Prat e Izquerdo (2000). Segundo Núñez e Ramalho (2015), a base orientadora da ação (BOA), na teoria de Galperin, constitui o elemento estrutural da ação que possibilita seu planejamento, a direção da execução e o controle ou a sua regulação. A BOA explicita o modelo da ação (o que é?) e o sistema de operações pelo qual se realiza a ação (como se faz) como também representa a referência do conhecimento desejado a ser aprendido. No Quadro 1, encontra-se representada a BOA da ação explicar. 


\section{Quadro 1}

Base de orientação para elaborar e escrever textos explicativos em Química

\begin{tabular}{|c|l|}
\hline Que significa? & $\begin{array}{l}\text { Tornar possível a compreensão de um fenômeno, um } \\
\text { resultado ou um comportamento para o leitor. }\end{array}$ \\
\hline O que se deve fazer? & $\begin{array}{l}\text { Produzir razões ou argumentos. Estabelecer relações, } \\
\text { especialmente de causa (Por que?) }\end{array}$ \\
\hline Resultado a ser obtido & $\begin{array}{l}\text { Um texto que proporcione conhecimentos ao leitor. } \\
\text { As razões ou os argumentos devem ser referidos a um } \\
\text { objeto. Há suficientes razões considerando-se os conhe- } \\
\text { cimentos que se devem ter. } \\
\text { Existem relações de causa. O léxico deve ser ade- } \\
\text { quado, da Química e ao objetivo da explicação. }\end{array}$ \\
\hline Como elaborar o texto & $\begin{array}{l}\text { Colocar um título. Apresentar uma estrutura de texto que } \\
\text { contenha problema-solução e relações de causa-efeito. } \\
\text { Para isso, é necessário construir frases com relações } \\
\text { causais ou expressas por meio de conectores, tais } \\
\text { como: porque, iá que, visto que, entre outros. Avaliar } \\
\text { também a necessidade de se fazer algum esquema. }\end{array}$ \\
\hline
\end{tabular}

Fonte: Prat e Izquerdo (2000) Adaptado.

\section{O contexto e os participantes do estudo}

Oestudo foi realizado com 24 estudantes de um curso de Licenciatura em Química, no contexto da disciplina Estágio e Prática de Ensino de Química II. Quase todos os estudantes (75\%) estavam finalizando o terceiro ano do curso. Dos estudantes, $45 \%$ são do sexo feminino e 55\%, do masculino. Do total, 75\% fez o Ensino Médio em instituições escolares públicas. A média de idade é de 20,5 anos. Nesse momento do curso, todos já cursaram as disciplinas específicas básicas de Química da formação assim como Didática Geral e Psicologia Educacional. Para fins de análises dos resultados, os licenciandos são identificados por um código (L), que expressa o curso para todos, e por números (1, 2, 3 etc), que identificam cada um deles. 


\section{Metodologia da pesquisa}

No estudo, optou-se pela prova pedagógica (CEREZAL; FIALLO, 2010) com perguntas de conteúdo, diretamente relacionadas com os objetivos da pesquisa, cujas respostas podem oferecer informações (ou falta delas) significativas em relação aos conhecimentos profissionais. Nas perguntas abertas, não se limitou ou se preestabeleceu a forma de responder e não se definiram variantes de respostas, por isso houve a liberdade para responder de acordo com o modo como se interpretou a questão.

Essa prova pedagógica, elaborada pelos pesquisadores, foi validada por um especialista na temática e aplicada, inicialmente, a cinco estudantes da licenciatura como pré-teste para testar a clareza e a sua compreensão, o que possibilitou a elaboração da versão definitiva. A aplicação da prova pedagógica validada ocorreu em sala de aula. Inicialmente, explicou-se aos licenciandos como deveriam respondê-la, o tempo disponível para esse propósito assim como a disponibilidade de espaço para escrever o texto explicativo. A prova pedagógica foi dividida em duas partes. A primeira continha perguntas para caracterizar o perfil dos licenciandos, e a segunda era composta das 10 seguintes questões:

A) $\bigcirc$ que é explicar propriedades das substâncias e dos materiais no contexto da Química como ciência? B) Suponha que, como parte da comunidade científica da Química, você deve explicar porque o $\mathrm{NaCl}$ é um sólido que, nas condições do ambiente, apresenta elevada temperatura de fusão. Elabore um texto explicativo para tal propósito.

As respostas à primeira pergunta aberta foram tratadas pela técnica de Análise Temática de Conteúdo. Os procedimentos da análise de conteúdo, como explica Minayo (2010), levam a relacionar não só estruturas semânticas (significantes) com estruturas sociológicas (significados) dos enunciados como também relacionar a articulação da superfície dos enunciados dos textos com fatores que determinam suas características. Procuramos, dessa forma, abranger e sumarizar dados, além de prover uma descrição primária, o que levou a suscitar novas preocupações na medida em que as informações foram expostas de forma clara, o que permitiu uma aproximação à compreensão do objeto de estudo. 
A análise das respostas foi amparada por procedimentos de cunho quantitativo e qualitativo, de forma complementar. Nesse sentido, os dados foram tratados por meio da técnica estatística de análise de frequência (dimensão quantitativa), organizados em tabelas e, depois, analisados com atenção voltada às peculiaridades e às relações entre as categorias propostas para a análise, considerando o que era significativo, relevante ou ausente (dimensão qualitativa). As tabelas foram analisadas de forma tal a dar sentido aos dados e a responder as questões de estudo.

Para a análise das respostas à terceira questão e a determinação dos níveis de desenvolvimento da habilidade explicar, em relação às propriedades do $\mathrm{NaCl}$, foram usados os critérios de avaliação desenvolvidos por Jorba (2000), apresentados no Quadro 2.

\section{Quadro 2}

\section{Critérios de avaliação da habilidade explicar}

\begin{tabular}{|c|}
\hline \\
\hline 1. PERTINÊNCIA \\
\hline $\begin{array}{l}\text { As proposiçães, de forma geral, são coerentes e se referem ao objeto da explicação (as proprie- } \\
\text { dades das substâncias). }\end{array}$ \\
\hline \\
\hline O registro da língua se adequa à função e aos interlocutores do texto. \\
\hline 2. \\
\hline $\begin{array}{l}\text { Há um número suficiente de proposições para modificar o estado do conhecimento, que se } \\
\text { podem considerar aceitas pela comunidade científica. }\end{array}$ \\
\hline \multirow{2}{*}{$\begin{array}{l}\text { As proposições contêm explicitamente relações do tipo causal. } \\
\text { 3. PRECISÃO }\end{array}$} \\
\hline \\
\hline Utiliza o léxico levando em conta: \\
\hline \multirow{2}{*}{$\begin{array}{l}\text { - a precisão dos vocábulos de acordo com o modelo de ligação iônica; } \\
\text { - a adequação dos vocábulos que têm significados diferentes na linguagem coloquial e, especi- } \\
\text { ficamente, em relação ao modelo teórico de ligação iônica. }\end{array}$} \\
\hline \\
\hline 4. VOLUME DE CONHECIMENTOS \\
\hline \multirow{3}{*}{$\begin{array}{l}\text { O volume de conhecimentos é adequado em relação ao nível de explicação solicitado. } \\
\text { 5. ORGANIZAÇÃO DO TEXTO } \\
\text { O texto se organiza de acordo com o modelo explicativo, no qual se relacionam os fatos de } \\
\text { acordo com a lógica da explicação. São utilizados conectores causais. }\end{array}$} \\
\hline \\
\hline \\
\hline \\
\hline
\end{tabular}

Fonte: Dados da pesquisa. 


\section{O conhecimento da explicação na Química como ciência}

Ser capaz de estabelecer a diferença entre explicação científica e explicação escolar é essencial para os professores de Química desenvolverem atividades discursivas que contribuam para os estudantes compreenderem o lugar da explicação nas ciências e na sua aprendizagem. Essa é, por sua vez, uma dificuldade apresentada por professores que ensinam ciências, na opinião de McNeill e Krajcik (2008).

Na prova pedagógica, foi solicitado aos licenciandos expressar o que é explicar cientificamente propriedades de substâncias e de materiais em Química. As respostas categorizadas estão explicitadas no Quadro 3. Como se observa, apenas 20,8\% dos licenciandos fazem referência à dimensão causal da explicação, ou seja, relacionam o nível macroscópico la fenomenologia) com o nível microscópico, como uma das características da explicação científica.

\section{Quadro 3}

Percentual de respostas da pergunta: $O$ que é explicar propriedades das substâncias em Química como explicação científica?

\begin{tabular}{|l|c|}
\hline \multicolumn{1}{|c|}{ Categorias } & Quantidade (\%) \\
\hline $\begin{array}{l}\text { É mostrar para o aluno por que determinadas subs- } \\
\text { tâncias apresentam determinadas propriedades, } \\
\text { segundo um modelo teórico }\end{array}$ & 20,8 \\
\hline Transmitir o que foi estudado por alguém & 16,6 \\
\hline Fazer que aluno entenda & 58,3 \\
\hline $\begin{array}{l}\text { Descrever ou passar um conhecimento ou uma } \\
\text { informação }\end{array}$ & 8,2 \\
\hline $\begin{array}{l}\text { Demonstrar os motivos e as circunstâncias do por- } \\
\text { quê dessas propriedades }\end{array}$ & 8,2 \\
\hline $\begin{array}{l}\text { Relacionar, em termos de causa e efeito, o nível } \\
\text { microscópico, ou seja, a constituição com o que se } \\
\text { observam as propriedades }\end{array}$ & 20,8 \\
\hline Diferenciar e identificar a estrutura da substância & 12,5 \\
\hline
\end{tabular}

Fonte: Dados da pesquisa. 
A explicação entendida como uma forma de mostrar, transmitir, compreender e entender foram as categorias que mais apareceram, com um total de $91,5 \%$ dos licenciandos. Essa característica de proporcionar compreensão de "algo" tem sido apontada por Ogborn, Kress, Martins e Mcgillicuddy (1998). Não obstante, essa compreensão, para 79,1\% dos licenciandos, tem uma dimensão didática pelo fato de confundirem a explicação científica (produzidas na atividade científica) com as explicações de professores ou estudantes no contexto escolar, as últimas caracterizadas nos estudos de Martins, Ogborn e Kress (2018).

Os futuros professores demonstram que não conseguem diferenciar a explicação científica da explicação no contexto do ensino de ciência. De acordo com Osborne e Petterson (201 1), isso ocorre pelo fato de não ficar estabelecida uma diferença entre explicar algo (explicação científica, no contexto das ciências) e explicar algo a alguém (usar uma explicação disponível e fazê-la compreensível aos estudantes).

Quando se pretende explicar algo a alguém, isso pode ser feito por meio da transmissão ou do esclarecimento de algo que já é conhecido, o que não ocorre na explicação científica. Nesta, é necessário elaborar uma explicação do porquê de algo acontecer ou de ter certas propriedades, quando não se dispõe de uma já elaborada. É importante que, no contexto escolar, os estudantes possam elaborar suas próprias explicações baseadas em conhecimentos científicos já estabelecidos, as quais deverão ser comparadas com as propostas pela ciência para atestar a sua veracidade. Segundo Núñez e Ramalho (2015), espera-se que não só os professores expliquem os conteúdos da ciência mas também que os estudantes sejam capazes de construir explicações em sala de aula.

Esse resultado evidencia dificuldades dos licenciandos na distinção entre a explicação científica e a presente na educação escolar. Ser capaz de estabelecer essa diferença é um conhecimento de natureza epistemológica e didática, essencial para a educação científica dos estudantes em Química.

Nos fragmentos de texto reproduzidos a seguir, estão ideias de licenciandos que revelam melhor os sentidos que eles atribuem à explicação científica das propriedades físicas e dos materiais em Química.

L2. É relacionar o que observamos a nível macroscópico das substâncias e materiais com a sua constituição microscópica. Explicar 
as propriedades relacionando com a estrutura química das substâncias e dos materiais (L2, 2017).

L3. É utilizar o conhecimento até então produzido pela ciência referente a esta temática, e explicá-lo de modo a tornar acessível ao entendimento do aluno (L3, 2017).

L8. A explicação científica das propriedades das substâncias e dos materiais, passa basicamente pela abordagem de aspectos como a composição de tais substâncias/materiais, as interações "presentes" nas substâncias/materiais estudados, variáveis que influenciam nas propriedades dos mesmos (L8, 2017).

L15. Consiste em estabelecer e utilizar teorias para explicar microscopicamente o que é observado no macroscópico, fazendo uso de modelos e representações para promover tal explicação (L 15, $2017)$.

\section{A habilidade de elaborar textos explicativos sobre propriedades físicas das substâncias e dos materiais}

A habilidade de elaborar o texto escrito para explicar uma das pro14 priedades físicas do $\mathrm{NaCl}$, ou seja, apresentar elevada temperatura de fusão nas condições ambientais, foi avaliada na questão 3 da prova pedagógica.

As análises dos textos produzidos pelos licenciandos foram realizadas considerando os critérios estabelecidos por Jorba (2000). No Quadro 4, estão os resultados para o critério de pertinência do texto.

\section{Quadro 4}

Percentual de respostas sobre a pertinência do texto

\begin{tabular}{|c|c|c|c|c|}
\hline Pertinência & Correto & $\begin{array}{c}\text { Parcialmente } \\
\text { Correto }\end{array}$ & Incorreto & Ausente \\
\hline $\begin{array}{l}\text { As proposições, de forma geral, são } \\
\text { coerentes e se referem ao objeto da } \\
\text { explicação las propriedades das } \\
\text { substâncias) }\end{array}$ & 29,2 & 37,5 & 33,3 & 0,0 \\
\hline $\begin{array}{l}\text { Expressa-se com clareza, de maneira } \\
\text { que a leitura facilita ao interlocutor } \\
\text { compreender a intencionalidade do } \\
\text { autor do texto }\end{array}$ & 29,2 & 37,5 & 33,3 & 0,0 \\
\hline $\begin{array}{l}\text { O registro da língua se adequa à fun- } \\
\text { ção aos destinatários do texto }\end{array}$ & 50,0 & 20,8 & 29,2 & 0,0 \\
\hline
\end{tabular}


Fonte: Dados da pesquisa.

Nesse Quadro, constata-se que, no geral, é baixo o número de licenciandos que usam proposições coerentes relativas ao objeto da explicação $(29,2 \%)$. Esse mesmo percentual é observado quanto à segunda pertinência, que diz respeito à intencionalidade de explicar a alta temperatura de fusão da substância.

Quanto à terceira pertinência, verifica-se que 50\% dos licenciandos usam um registro da língua adequado à explicação e aos destinatários do texto, ou seja, de alguma forma fazem referência ao estabelecimento de relações causais.

A completude do texto escrito diz respeito à quantidade e qualidade das proposições usadas no texto explicativo. No Quadro 5, observa-se que, no geral, os licenciandos não produzem textos com suficientes proposições que possam dar conta de uma explicação mais completa e satisfaçam as exigências desse tipo de texto, considerando se tratar de um fenômeno multicausal. Por sua vez, embora haja textos de extensão limitada, neles se expressam relações simples de causa-efeito, encontrado nas respostas de 54,4\% dos licenciandos.

\section{Quadro 5}

Percentual de respostas sobre a completude do texto

\begin{tabular}{|l|c|c|c|c|}
\hline \multicolumn{1}{|c|}{ Completude } & Correto & $\begin{array}{c}\text { Parcialmente } \\
\text { Correto }\end{array}$ & Incorreto & Ausente \\
\hline $\begin{array}{l}\text { Há um número suficiente de } \\
\text { proposições para modificar o } \\
\text { estado do conhecimento, que } \\
\text { se podem considerar aceitas } \\
\text { pela comunidade científica. }\end{array}$ & 10,0 & 5,0 & 85,0 & 0,0 \\
\hline $\begin{array}{l}\text { As proposições contêm expli- } \\
\text { citamente relações do tipo } \\
\text { causal. }\end{array}$ & 54,2 & 20,8 & 25,0 & 0,0 \\
\hline $\begin{array}{l}\text { Utiliza outra linguagem, como } \\
\text { esquema, figuras, etc., para } \\
\text { completar a informação do } \\
\text { texto. }\end{array}$ & 0,0 & 0,0 & 0,0 & 100 \\
\hline
\end{tabular}

Fonte: Dados da pesquisa. 
Para explicar em Química, faz-se necessário saber relacionar os seus três níveis representacionais (JOHNSTONE, 1982) a fim de elaborar raciocínios e textos escritos com argumentos adequados, coerentes, complexos, científicos, rigorosos e convincentes.

Conhecer as causas de um fenômeno não é tarefa fácil, por se tratar de um processo complexo, que vai do fenômeno à sua essência e vice-versa, e por existirem várias causas para cada um (NúÑ̃EZ; RAMALHO, 2015). É necessário ainda considerar as possíveis consequências de um fenômeno. Além disso, esse conhecimento implica definir as possibilidades ou não de usar um dado modelo teórico, considerando os limites de aplicação do conhecimento científico.

Os licenciandos, ao elaborarem a explicação, não se referem à energia de rede do cloreto de sódio como um fator que influencia a elevada temperatura de fusão. Assim, as respostas revelam que eles não pensam em termos de uma organização mais complexa de íons, como se estabelece no modelo teórico da ligação iônica, conforme tem assinalado Mendoça e Justi (2009). Essa dificuldade foi identificada por Taber (1994) para professores de Química. Segundo ele, isso ocorre pelo fato de os professores utilizarem a 16 regra de octeto como modelo do ensino da ligação iônica, e não o modelo eletrostático, o que, na opinião de Coll e Treagust (2003), restringe o modelo de ligação iônica à ideia de transferência de elétrons, formação e atração dos íns.

Vale ressaltar que o uso de diversas representações semióticas tem importância na explicação científica, o que pode favorecer os processos de comunicação e de construção do conhecimento científico. A explicação científica expressa entidades que, muitas vezes, não são conhecidas.

A linguagem científica é uma linguagem específica, diferente da linguagem do cotidiano, sendo necessário, portanto, que seu ensino ocorra de forma explicita. Aprender ciências significa aprender a usar, de forma correta e consciente, a linguagem das ciências (LEMKE, 1997; SUTTON, 2003).

$\bigcirc$ Quadro 6 evidencia que os licenciandos não usam outra linguagem, como esquemas, figuras, etc., nos textos elaborados. Esse é um fato que chama a atenção face à diversidade de representações semióticas que podem ser usadas em química. 
Jimenez-Aleixandre (2003) enfatiza a importância das imagens no discurso científico, em especial, na visualização das entidades não visíveis. Essas imagens têm uma linguagem própria, sendo necessário, na opinião da autora, dedicar tempo para os estudantes aprenderem a aproveitar todas suas possibilidades na medida do possível. Por sua vez, esse tipo de linguagem apresenta dificuldades para os estudantes, pelo fato de estar relacionada a determinados modelos científicos.

Outro elemento chave que atesta a qualidade do texto explicativo é a precisão dos vocábulos usados no texto. A linguagem científica apresenta características bem determinadas: é precisa, não ambígua, rigorosa, formal, impessoal e, muitas vezes, hipotética. Isso exige, no texto explicativo, precisão e uso adequado da linguagem científica, que, nesse caso, diz respeito aos modelos e às teorias científicas da ligação química, da estrutura atômica e da tabela periódica.

A precisão do texto é uma qualidade avaliada nos textos escritos produzidos pelos licenciandos. Os resultados dessa avaliação se encontram no Quadro 6.

\section{Quadro 6}

\section{Percentual de respostas sobre a precisão do texto}

\begin{tabular}{|c|c|c|c|c|}
\hline Precisão & Correto & $\begin{array}{c}\text { Parcialmente } \\
\text { Correto }\end{array}$ & Incorreto & Ausente \\
\hline $\begin{array}{l}\text { Precisão dos vocábulos de } \\
\text { acordo com o modelo de liga- } \\
\text { ção iônica. }\end{array}$ & 45,8 & 12,5 & 41,7 & 0,0 \\
\hline $\begin{array}{l}\text { Uso adequado dos vocábulos } \\
\text { que têm significado diferente } \\
\text { na linguagem coloquial e, } \\
\text { especificamente, em relação } \\
\text { ao modelo teórico de ligação } \\
\text { iônica. }\end{array}$ & 41,7 & 16,7 & 41,6 & 0,0 \\
\hline
\end{tabular}

Fonte: Dados da pesquisa.

A prática da Química como ciência se relaciona com a atividade em três níveis de representação de explicação, de forma integrada. Johnstone (1982) denomina esses níveis de descritivo e funcional, de representação e 
explicativo. No nível descritivo e funcional, os químicos manipulam, observam e descrevem propriedades dos materiais assim como também as transformações químicas dos materiais por meio das mudanças de suas propriedades. Para explicar o comportamento das substâncias e dos materiais, são utilizados modelos teóricos, tais como os de átomos, moléculas, íons, ligação química, dentre outros. As formas de representar as partículas constituintes das substâncias e dos materiais, ou seja, as fórmulas químicas e as mudanças químicas, nesse caso, as equações químicas, constituem os principais recursos no nível de representação.

Uma leitura do Quadro 7 possibilita constatar que 45,8\% dos licenciandos usam, de forma correta, os termos científicos dos modelos teóricos necessários para a explicação, nas respostas consideradas limitadas, enquanto $41,7 \%$ não o fazem. Quando utilizam, de forma precisa, os termos da linguagem química, verifica-se que atentam para a diferença entre a linguagem científica e a coloquial.

Esses resultados coincidem com as investigações de Sarda e Sanmarti (2000) em relação à falta de rigor, precisão, estruturação e coerência dos textos escritos por estudantes da educação básica nas aulas de ciências.

Os licenciandos que não utilizam com precisão os termos próprios da linguagem dos modelos da ligação iônica $(41,7 \%)$ cometem erros, dentre os quais se destacam:

- confundir íons com moléculas;

- atribuir ao composto iônico estrutura molecular;

- atribuir a causa da alta temperatura de fusão do sólido a interações moleculares dipolo-dipolo.

Na opinião de Borsese (2000), no caso da Química, a linguagem é específica, uma vez que cada símbolo contém um número elevado de significados. Além disso, por meio da linguagem, não só são nomeadas as transformações das substâncias nos níveis macro e microscópico mas também são registradas, codificadas e transformadas em elementos do pensamento e da comunicação.

Esses erros podem estar relacionados a diversas dificuldades de aprendizagem da Química, discutidas por Núñez e Ramalho (2017), quando 
caracterizam a natureza dos conhecimentos químicos, a linguagem da Química e até as formas de ensino, dentre outras.

volume de conhecimento foi outro critério para avaliar o texto explicativo elaborado pelos licenciandos. Os resultados dessa avaliação estão presentes no Quadro 7.

\section{Quadro 7}

Percentual de respostas sobre o volume de conhecimentos do texto

\begin{tabular}{|c|c|c|c|c|}
\hline Volume de conhecimentos & Correto & $\begin{array}{c}\text { Parcialmente } \\
\text { Correto }\end{array}$ & Incorreto & Ausente \\
\hline $\begin{array}{l}\text { O volume de conhecimentos é } \\
\text { adequado em relação ao nível } \\
\text { de explicação solicitado. }\end{array}$ & 0 & 29,2 & 70,8 & 0,0 \\
\hline
\end{tabular}

Fonte: Dados da pesquisa.

\section{Quadro 8}

Percentual de respostas sobre a organização do texto

\begin{tabular}{|c|c|c|c|c|}
\hline Organização do texto & Correto & $\begin{array}{c}\text { Parcialmente } \\
\text { Correto }\end{array}$ & Incorreto & Ausente \\
\hline $\begin{array}{l}\text { O texto se organiza de acordo } \\
\text { com o modelo explicativo, no } \\
\text { qual se relacionam os fatos } \\
\text { conforme a lógica da expli- } \\
\text { cação. Usam-se conectores } \\
\text { causais. }\end{array}$ & 23,8 & 42,9 & 33,3 & 0,0 \\
\hline
\end{tabular}

Fonte: Dados da pesquisa.

Foi constatado que os licenciandos, ao escrever utilizando mito pouco as estruturas sintáticas necessárias ao texto explicativo, especificamente as conjunções causais. Não revelaram ter consciência da coerência global que deve ter esse tipo de texto escrito, questão que tem sido assinalada por Márquez (2008) como uma dificuldade dos estudantes na escrita de textos, nas aulas de ciências.

A explicação científica das propriedades das substâncias e dos materiais deve ser realizada usando modelos e teorias científicas sobre a sua 
estrutura para que, assim, estes possam ser considerados "causa" do comportamento físico, considerando os limites e as possibilidades de aplicação desses conhecimentos científicos. Dos licenciandos, apenas 23,8\% utilizam, embora de forma limitada se considerado o volume de conhecimentos necessários, os modelos teóricos da estrutura das substâncias, em especial os modelos de ligação iônica, de partículas e da estrutura cristalina da substância. 42,9\% fazem uso desses modelos parcialmente, mas limitado à referência de apresentar ligação iônica, na qual os íons se encontram fortemente unidos e não fazem referência à estrutura cristalina e à sua estabilidade. Dos licenciandos, 33,3\% responderam de forma incorreta.

Os que responderam corretamente e parcialmente usaram poucos conetores causais, necessário ao texto explicativo, o que explica uma quantidade pequena de proposições apresentadas nos textos escritos. Essa é uma dificuldade apontada por Quilez (2016), quando se refere a diversas pesquisas ressaltando que esses tipos de conetores precisam de uma atenção especial na compreensão e no uso da linguagem científica pelos estudantes. Os textos abaixo são representativos dessa análise:

L4. A interação do $\mathrm{NaCl}$ é do tipo dipolo-dipolo, sendo esta interação muito forte e para ser quebrado o refículo cristalino do $\mathrm{NaCl}$ precisa de uma grande quantidade de energia laumento da temperatura) para fundir $(44,2017)$.

L13. O Cloreto de sódio apresenta ligação de caráter iônico, fazendo com que a interação entre os constituintes líon sódio e íon cloreto) forme uma rede resultando em um sólido cristalino. Esta rede aumenta a interação aumentando a temperatura de fusão, pois a energia necessária para 'separar' os cristais da rede será mais alta (L13, 2017).

L 20. O Cloreto de sódio, por ser um composto iônico e ter uma energia de rede cristalina muito elevada devido ao seu estado organizacional tem grande estabilidade, visto que necessita de grande energia para se fundir (Parcialmente correto) $(L 20,2017)$.

Os textos explicativos produzidos pelos licenciandos, embora a disponibilidade de espaço na folha de resposta, caracterizam-se por respostas limitadas à pergunta da situação da prova pedagógica. Em nenhum dos casos, à explicação antecedeu um texto expositivo que situasse o tema, fizesse um resumo que contivesse a ideia mais importante, desenvolvesse o tema com 
novas ideias ou ainda apresentasse uma conclusão, elementos estruturais que fazem parte do texto escrito explicativo, segundo Sanmarti (2000).

No estudo, os achados coincidem com outras pesquisas, como a de Ebbers e Rowell (2002), Núñez e Ramalho (2015), as quais evidenciaram dificuldades de estudantes para produzir textos explicativos, segundo as proposições de Sanmarti (2000).

\section{Conclusões}

conhecimento relativo à explicação científica e à produção de textos explicativos científicos como habilidade cognitivo-linguística e como procedimento das ciências torna-se um conhecimento profissional relevante para os licenciandos em Química. A formação dos futuros professores de Química deve levar em conta o que Sutton (2003) chamou a atenção: o professor de ciências ser um professor de língua, e todas as aulas de ciências serem aulas de língua, o que implica uma formação para enfrentar essa tarefa profissional.

texto explicativo, importante meio de comunicação no âmbito da ciência, tem um papel essencial nos processos de investigação científica. Dessa forma, por ser a educação química um processo de enculturação científica dos estudantes, os professores devem ter um adequado conhecimento profissional sobre o que é e sobre como se produz um texto explicativo.

Na pesquisa, se constatou que os futuros professores de Química, na sua maioria, consideram a explicação científica com uma via para a transmissão e a compreensão das propriedades físicas de substâncias e materiais, sendo associada a uma dimensão didática e não epistemológica. Isso revela fragilidades quanto ao conhecimento dessa habilidade na Química como ciência, muito relacionado com o domínio de conhecimentos sobre a natureza das ciências.

Em relação à habilidade de escrever o texto explicativo solicitado na prova pedagógica, constataram-se dificuldades na qualidade dos textos escritos. Embora os textos estejam pautados na relação entre a estrutura e a propriedade que devem ser explicadas, há proposições frágeis em relação ao conhecimento da Química, caracterizado pela ausência de elementos figurativos, como também há presença de imprecisões em vocábulos próprios das ciências, o que evidenciou um baixo volume de conhecimentos adequados 
para o nível de explicação solicitado. Construir um texto explicativo, no âmbito da ciência, é difícil para os futuros professores, pelo fato de ser uma habilidade comunicativa que envolve as dimensões cognoscitivas e linguísticas e requer não só a compreensão da natureza da ciência como também o domínio de diversos modelos e teorias científicas, dentre outros.

Em relação à organização do texto, também se constatou pouco domínio do conhecimento profissional na produção do texto logicamente concatenado, estruturado com conetores a partir dos quais se relaciona a propriedade com a essência em termos de relações causais.

Essa situação permite concluir que os licenciandos apresentam dificuldades para dispor de uma adequada orientação da ação ou modelo mental da ação escrever textos explicativos como conhecimento profissional, na qual se integram as operações e os modelos teóricos necessários à demanda cognitiva em questão.

Os resultados evidenciam a necessidade de se atribuir importância à formação inicial dos graduandos quanto aos processos de comunicação da ciência, para que eles possam pensar sobre esses processos e aprender a ensiná-los no contexto da educação científica.

\section{Nota}

1 Agradecimento: Ao CNPQ pelo apoio financeiro na realização da pesquisa.

\section{Referencias}

BORSESE, Aldo. Comucación, lenguaje y enseñanza. Educación Quimica, Ciudad México, v. 11, n. 2, p. 220-227, abr./jun. 2000.

BRAATEN, Melissa; WINDSCHITL, Mark. Working toward a stronger conceptualization of scientific explanation for science education. Science Education, London, v. 95, p. 639-669, may 2011.

CARVAlHO, Anna Maria Pessoa. As condições de diálogo entre professores e formador para um ensino que promova a enculturação científica dos alunos. In: DALBEN, Ângela; DINIZ, Júlio; LEAL, Leiva; SANTOS, Lucíola (Org.). Didática e práticas de ensino. Belo Horizonte: Autentica, 2010. 
CEREZAL, Jorge Mesquita; FIALLO, Julio Rodríguez. Cómo investigar en Pedagogía. La Habana: Editorial Pueblo y Educación, 2010.

COLL, Richard; TREAGUST, David. Investigation of secondary school, undergraduate, and graduate learners' mental models of ionic bonding. Journal of Research in Science Teaching, Hoboken, n. 40, p. 464-486, 2003.

DUSCHL, Richard. La valoración de argumentaciones y explicaciones: promover estrategias de retroalimentación. Enseñanza de las Ciencias, Barcelona, v. 16, n. 1, p. 3-201, jan./ mar. 1998.

EBBERS, Margaretha; ROWELL, Pat. Scaffolding children's explanations. Primary Science Review, London, v. 74, p. 10-13, sept./oct. 2002.

GIERE, Ronald. Explaining Science: a cognitive approach. Chicago: The University of Chicago, 1988.

GILBERT, John. On the explanation of change in science and cognition. Science \& Education, Dordnecht, v. 8, n. 5, p. 543-557, set. 1999.

GILBERT, John; BOULTER, Carolyn; RUTHERFORD, Margaret. Models in explanations, part 1: horses for courses? International Journal of Science Education, London, v. 20, n. 1, p. 83-97, jan. 1998.

GÓMEZ, Alma Adriana Galindo. Construcción de explicaciones cientificas escolares. Revista Educación y Pedagogía, Medellin, v. 18, n. 45, p. 73-83, set./dez. 2006.

JIMÉNEZ-ALEIXANDRE, Maria, Pilar. Comunicación y lenguaje en la clase de ciencias. In: JIMÉNEZ ALEIXANDRE, Maria Pilar (Org.). Enseñar ciencias. Barcelona: Editorial Graó, 2003.

JOHNSTONE, Alex. Macro and microchemistry. The School Science Review, Portsmouth, v. 64, n. 227, p. 377-379, 1982.

JORBA, Jaime. La comunicación y las habilidades cognitivolinguísticas. In: JORBA, Jaime; GÓMEZ, Isabel; PRAT, Angels. Hablar y escrebir para aprender. Uso de la lengua en situación de enseñanza-aprendizaje desde las áreas curriculares. Barcelona: Editorial Sintesis, 2000.

L2. Questionário. Natal (RN), 10 abr. 2017.

L3. Questionário. Natal (RN), 10 abr. 2017.

44. Questionário. Natal (RN), 10 abr. 2017. 
L8. Questionário. Natal (RN), 10 abr. 2017.

L13. Questionário. Natal (RN), 10 abr. 2017.

L15. Questionário. Natal (RN), 10 abr. 2017.

L20. Questionário. Natal (RN), 10 abr. 2017.

LEMKE, Jay. Aprender a hablar ciencia. Lenguaje, aprendizaje y valores. Barcelona: Paidós, 1997.

MÁRQUEZ, Conxita, Bargalló. Aprender ciencias a través del lenguaje. Educar, Guardalajara, n. 33, p. 27-38, abr./jun. 2005.

La comunicación en el aula. In: MERINO Cristian Rubilar; GÓMEZ, Adriana Galindo; ADÚRIZ-BRAVO, Agustin (Org.). Áreas y estrategias de investigación en la didáctica de las ciencias experimentales. Barcelona: Universitar Autónoma de Barcelona, 2008. MARTINS, ISABEL; OGBORN, Jon; KRESS, Gunther. Explicando uma explicação. Ensaio pesquisa em educação em ciências, Belo Horizonte, v. 1, n. 1, p. 1-14, 1999.

MCNEILL Katherine; KRAJCIK, Joseph. Scientific explanations: characterizing and Evaluating the Effects of Teachers' Instructional Practices on Student Learning. Journal of Research in Science Teaching, Hoboken, v. 45, n. 1, p. 53-78, 2008.

MCNEILL, Katharine; LIZOTTE, David. J.; KRAJCIK Joseph. Supporting students' construction of scientific explanations by fading scaffolds in instructional materials. Journal of the Learning Sciences, Philadelphia, v. 15, n. 2, p. 153-191, 2006.

MENDONCCA, Paula Cristina Cardoso; JUSTI, Rosária. Favorecendo o aprendizado do modelo eletrostático: análise de um processo de ensino de ligação iônica fundamentado em modelagem - Parte I. Educación Química, Ciudad México, v. 20, n. 3, p. 282-293, jul./ set. 2009

MINAYO, Maria, Cecilia, de Souza. O desafio do conhecimento: pesquisa qualitativa em saúde. 12. ed. São Paulo: Hucitec, 2010.

MORAES, Roque; GALIAZZI, Maria do Carmo; RAMOS, Mauirivan. Güntzel. In: MORAES, Roque; VALDEREZ, Maria do Rosario (Org.). Pesquisa em sala de aula: tendências para a educação de novos tempos. Porto Alegre: EDIPUCRS, 2002.

MORTIMER, Eduardo Fleury; VIEIRA, Ana Clara. Letramento científico em aulas de química para o ensino médio: dialogo entre linguagem científica e linguagem cotidiano. In: 
DALBEN, Angela; DINIZ, Julio; LEAL, Leiva (Org.). Coleção didática e práticas de ensino. Belo Horizonte: Autêntica, 2010.

NAGEL, Ernest. The structure of science: problems in the logic of scientific explanation. Indianapolis: Hackett Publishing Company, 1979.

NORRIS, Stephen; GUILBERT, Sandra; SMITH, Martha; HAKIMELAHI, Shahram; PHILLIPS, Linda. A theoretical framework for narrative explanation in science. Science Education, London, n. 89, p. 535-563, 2005.

NÚÑ̃EZ, Isauro, Beltrán; RAMALHO, Betania, Leite. A dispersão semântica na pesquisa educacional: implicações teórico-metodológicas. Revista Educação em Questão, Natal, v. 10 e 11 , n. 2/1, p. 96-114, jan./jun. 2000.

. Conhecimento profissional para ensinar a explicar processos e fenômenos nas aulas de Química. Revista Educação em Questão, Natal, v. 38, n. 52, p. 243-268, maio/ago. 2015.

Os itens de química do ENEM 2014: erros e dificuldades de aprendizagem. Acta Scientiae, Canoas, v. 19, n. 5, p. 799-816, set./out. 2017.

NÚÑ̃Z, Isauro, Beltrán. Vygotsky Leontiev Galperin - formação de conceitos e princípios didáticos. Brasília: Líber Livro, 2009.

OGBORN, Jon; KRESS, Gunther; MARTINS, Isabel; MCGILLICUDDY, Kieran. Formas de explicar: la enseñanza de las ciencias en secundaria. Madrid: Santanilla, 1998.

OSBORNE, Jonathan; PATTERSON, Alexeis. Scientific Argument and Explanation: A necessary distinction? Science Education, London, n. 95, p. 627-638, 2011.

$\mathrm{POZO}$, Juan Ignacio; POSTIGO, Yolanda Angón. Los procedimientos como contenidos escolares. Barcelona: Edebé. 2000.

PRAT, Angel; IZQUERDO, Mercé. Función del texło escrito en la construcción de conocimientos y en el desarrolo de habilidades. In: JORBA, Jaime; GÓMEZ, Isabel; PRAT Angels. Hablar y escrebir para aprender. Uso de la lengua en situación de enseñanza-aprendizaje desde las áreas curriculares. Barcelona: Editorial Sintesis, 2000.

QUILEZ, Juan. Pardo. ¿Es el profesor de Química también profesor de Lingua? Educación Química, Ciudad México, n. 27. p. 105-1 14, 2016.

SANMARTI, Neus. Didáctica de las ciencias en la educación secundaria obligatoria. Madrid: Editorial Síntesis S.S, 2000. 
A produção de textos científicos explicativos na formação inicial de professores de Química

Hablar, leer y escribir para aprender ciencia. In: FERNÁNDEZ, Pilar. Martínez

(Org.). La competencia en comunicación ligüística en las áreas del currículo. Madrid: Colección Aulas de Verano. MEC. 2007.

SARDA, Anna; SANMARTI, Neus. Enseñar a argumentar cientificamente: un reto de las clases de ciencias. Enseñanza de las Ciencias, Barcelona, v. 18, n. 3, p. 405-422, set./ dez. 2000.

SUTTON, Clive. Los profesores de ciencias como profesores de linguaje. Enseñanza de las Ciencias, Barcelona, v. 2, n. 1, p. 21-26, jan./abr. 2003.

TABER, Keith. Misunderstanding the ionic bond. Education in Chemistry, London, v. 31 , p. 100-103, 1994.

VYGOTSKI, Lev. Semyonovich. Pensamiento y linguaje. Madrid: Editorial Visor Distribuciones S. A, 1993. (Obras Escogidas).

WENZEL, Judith Scherer; MALDANER, Otavio Aloisio. A significação conceitual pela escrita e reescrita orientada em aulas de química. Química Nova, São Paulo, v. 37, n. 5, p. 908914, jun. 2014.

Universidade Federal do Rio Grande do Norte (Brasil)

Centro de Educação

Departamento de Práticas Educacionais e Currículo

Programa de Pós-Graduação em Educação Grupo de Pesquisa Estudo com foco na Teoria de P. Ya. Galperin E-mail: isaurobeltran@yahoo.com.br

Profa. Especialista Sandra Cristina Bezerra de Barros Universidade Federal do Rio Grande do Norte (Brasil) Centro de Ciências Humanas, Letras e Artes Departamento de Letras Grupo de Pesquisa Estudo com foco na Teoria de P. Ya. Galperin E-mail: scbbgtp@yahoo.com.br 
Recebido 9 out. 2018

Aceito 26 out. 2018 